of Von Orel. By means of the autocartograph the map can be plotted mechanically; and by clamping the height lever at a particular height, and keeping the stereoscopic pointer (in appearance) just in contact with the ground, a contour can be traced. The whole apparatus is elaborate and expensive, and it would need many pages to describe it at all adequately. It has possibly come to stay, though it has not yet been subjected to exhaustive tests. The stereoscopic method has the great advantage that it is possible by its means to draw the contours of a bare hillside, an impossibility with any point-by-point system; and this requirement of drawing contours must be met if air photo-surveying is to have any general application to topography. A topographical map of the normal type shows the ground features by approximate contours, which are controlled by a trigonometrical framework. At present, apart from the stereoscopic methods above mentioned, air photo-surveying is incapable of supplying the contours in open country. It is therefore, at present, only fitted for the survey of flat countries. It would be waste of time and money to prepare a ground plan by air methods and then go over the same ground again for the survey of the contours.

The position that has been reached is briefly this : Air photo-surveying is indispensable in war. In peace-time it has a unique field of usefulness for archæological purposes; for it has been shown by Colonel Beazeley, Mr. O. G. S. Crawford, and others, that air photographs may show ancient features that are invisible except from the air. For surveying purposes air photographs are probably, even now, of value for the mapping of estuaries and deltas, and possibly for the mapping of native towns on medium scales. It also appears likely that in flat or very gently undulating country the method can be used for the construction of cadastral plans without contours, with satisfactory speed and accuracy; and that in such circumstances the cost may be brought down to a practicable figure.

But at present, for the construction of contoured topographical maps, air photographs cannot be economically employed; and the same remark applies to the construction of maps and plans, on all scales, for all purposes, in hilly country. The future use

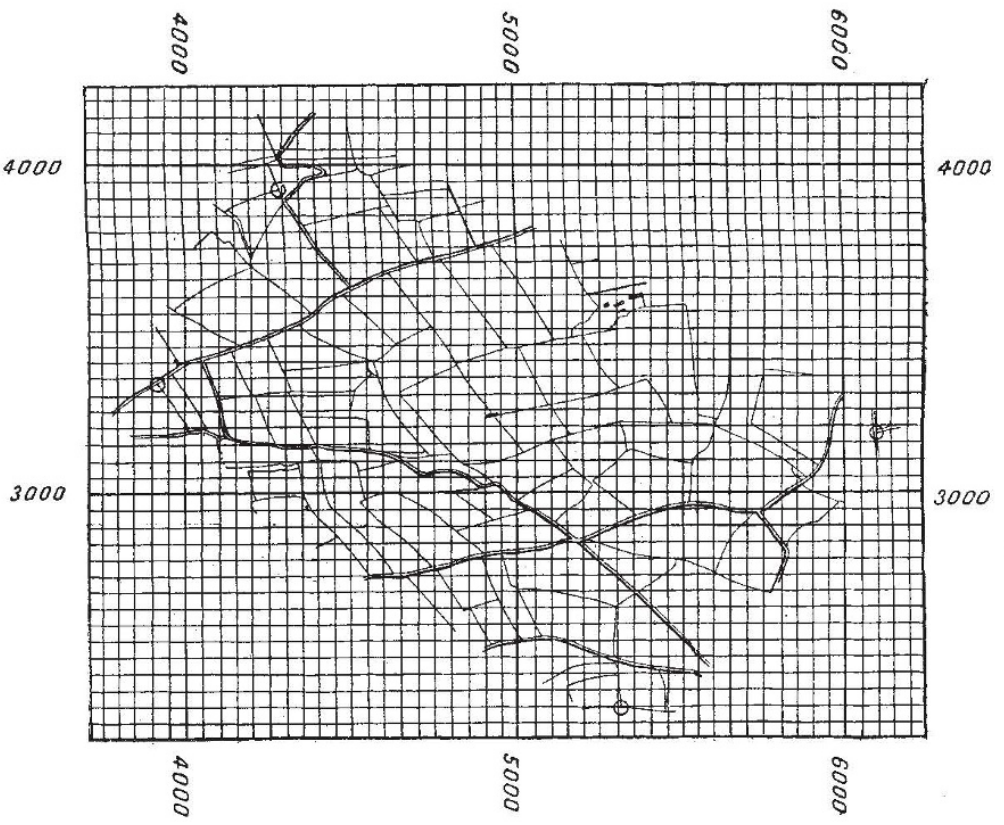

FrG. 3.-The map-grid. Reproduced, by permission of the Controller of H.M. Stationery Office, from the Report of the Air Survey Committee, No. I, 1923.

of air photographs, so far as concerns the general peace-time application of the method to the construction of accurate topographical maps, would appear to lie in the development of stereoscopic methods.

Any one interested in the subject may be advised to purchase the Report of the Air Survey Committee, which is clearly written, well illustrated, and contains much useful information, including a short bibliography.

C. F. Close.

\title{
The Reported Transmutation of Mercury into Gold.
}

I N Nature of March 29 last (pp. 459-460) we printed a communication by H. Nagaoka, Y. Sugiura, and T. Mishima " on the isotopes of mercury and bismuth revealed in the satellites of their spectral lines," at the end of which the authors stated that "if the above assumption as to the mercury nucleus is valid, we can perhaps realise the dream of alchemists by striking out a hydrogen-proton from the nucleus by a-rays, or by some other powerful methods of disruption." Following this statement, on July $2 \mathrm{x}$ the Morning Post reported from Berlin that Dr. A. Miethe, professor of photochemistry and astronomy in the Technical High School at Charlottenburg, had obtained gold from mercury by the prolonged action of a high-tension electric current upon it. In the absence of details, such a report could only be received with great reserve, for in the light of existing knowledge it seemed highly improbable that the amount of energy indicated to have been used would be sufficient to disrupt the mercury atom. An account of Prof. Miethe's work containing some definite experimental details is given in the issue of Die Naturwissenschaften for July I8, and we reproduce these in order that the claim advanced may be justly assessed.

Some thirteen months ago, Prof. Miethe adopted an improved type of mercury-vapour lamp, made by A. Jaenicke, for his experiments on the coloration of transparent minerals and glasses induced by ultraviolet rays. Early this year, he and his assistant, Dr. H. Stammreich, observed that when the current employed was too strong, the character of the emitted rays soon changed, and that a black deposit formed inside the lamp. (It is not stated if the lamp was of quartz or of glass.) This observation was confirmed by Jaenicke, who stated that on distilling the mercury recovered from old lamps of the improved type, he had 
found residues which he could not identify. He supplied Prof. Miethe with about 0.5 gram of the residues (which had been obtained from $5 \mathrm{~kg}$. of mercury), and the latter after careful investigation discovered that they contained gold, in addition to other substances which were undoubtedly present as impurities in the original mercury. According to Jaenicke, all the mercury used in the lamps had been twice distilled before use. In his successful experiments, Prof. Miethe always used a potential difference of 170 volts between the electrodes, which were in direct communication with the air outside ; the current was passed for 20-200 hours ; and the lamp consumed 400-2000 watts. It appeared probable that a minimum P.D. is essential, for no trace of gold was found in mercury lamps of the old type that had been long in use, and negative results were also obtained with lamps of the improved type when the P.D. was below a certain figure.

Owing to the minute quantity of gold obtained, namely, $0.1-0.0$ I mg., special precautions had to be taken in identifying it. In every test an amount of the original mercury equal to that which was removed from the lamp was analysed and found to be free from gold both by Prof. Miethe himself and independently by K. A. Hofmann; and it was proved that no gold was present in the electrical connexions. Further, the very delicate analytical methods elaborated by Haber failed to show with certainty the pre-existence of gold. When the residue left, after distilling off in vacuo the mercury from the black deposit, was treated with nitric acid, there remained yellow well-formed crystals, cubical and octahedral in form, and with a highly reflecting surface ; and when the mercury was removed from the deposit by volatilising it at a red heat, the resulting substance was bright gold in colour and of reniform or botryoidal shape. The substance was found to be malleable, it gave the streak of fine gold and the characteristic colour when the polished film was observed by doubly reflected light. It was easily soluble in aqua regia, and on evaporation the solution gave crystals precisely similar to those obtained when ordinary gold is so treated. Identical results were also obtained by the purple-of-Cassius test. It was not possible to make an atomic-weight determination or to attempt to prove the production of helium, hydrogen, $\alpha$ - or $\beta$-rays.

\section{Obituary.}

Str James J. Dobbie, F.R.S.

IAMES JOHNSTON DOBBIE, whose death occurred at Fairlie, Ayrshire, on June I9, was born at Glasgow in 1852 . He was educated at the High School of Glasgow, and entered the University of Glasgow, where he took his Arts degree with firstclass honours in Natural Science. Later he worked at Leipzig in the laboratory of Wislicenus. There being no science degree at Glasgow in those days, he went to Edinburgh, and graduated as B.Sc., proceeding later to the Doctor's degree. He was elected to a Clark Fellowship at Glasgow University, and returned there and taught the class of mineralogy.

Sometime before this Dobbie had made the acquaintance of Ramsay, then a young assistant in the chemistry department of the university. Ramsay first introduced him to organic chemistry, and they read together Schorlemmer's well-known "Chemistry of the Carbon Compounds." Ramsay invited him to join in an investigation on the constitution of quinine, scarcely anything being known of the constitution of the alkaloids at that time. By oxidation with alkaline permanganate they obtained pyridine tri-carboxylic acids, which they identified, thus establishing for the first time the connexion between the alkaloids and the pyridine bases.

Soon after this Ramsay was elected to the chair of chemistry at Bristol, and Dobbie succeeded him at Glasgow. Here he continued his work on alkaloids, and also took an active share in establishing the Glasgow and West of Scotland Section of the Society of Chemical Industry, of which he was the first secretary.

In I 884 Dobbie was elected to the chair of chemistry in the newly founded University College of North Wales at Bangor. His first work was to get laboratories built and equipped, and to organise the teaching of his department. He resumed his research work on alkaloids, and made, in particular, a very complete investigation of the alkaloids of Corydalis cava, working out the constitution of corydaline and investigating also the structure of the associated alkaloids. This work, necessarily complicated, was rendered still more difficult by the high cost of the alkaloids, so that the investigation had to be carried out with very small quantities of material : the results were communicated in a series of papers to the Chemical Society from I 892 to I904. A little later he took up the study of the relation between the ultra-violet absorption spectra and the constitution of organic compounds, working at first with the late Sir W. N. Hartley, and later with other workers. In particular, they showed how the method could be applied to determine the constitution of tautomeric bodies.

Dobbie's work at Bangor, however, was by no means limited to that of his own department. He felt that, in an agricultural country such as North Wales, one of the proper functions of the college was to do everything possible to promote its chief local industry. He spent several vacations on the Continent studying methods of agricultural education, and started a campaign for the founding of an agricultural department at Bangor. Funds had to be collected and the interest of the land-owning classes and the farmers, as well as that of the Board of Agriculture, aroused. After several years of strenuous work the agricultural department was at length inaugurated in $\mathbf{1} 894$. Courses were provided leading to a diploma and later to a degree in agriculture, while a comprehensive scheme of extension lectures and experiments was devised. This was the first agricultural department to be founded in connexion with a University College, and it is impossible to overrate the importance of Dobbie's pioneer work at Bangor in the development of agricultural education. He took a leading part in the work of the foundation of the University of Wales, and the college and the university owed much in these early days to his sane judgment and great administrative skill.

$$
\text { NO. } 2858 \text {, VOL. I I } 4 \text { ] }
$$

